\title{
Can Online Collaborative Work Offer a Solution to the Over Crowded Classes in Egyptian Universities?
}

\author{
Dr Nashwa Ismail
}

Institute of Educational Technology, The Open University, United Kingdom

\section{Dr Gary Kinchin}

\section{Department of Education, University of Southampton, United Kingdom}

\begin{abstract}
:
This study investigates tutors' perception towards students' group work when they learn online as a proposed solution for overcrowded classes. The study context is the Egyptian Higher Education (HE) system and the research participants were $20 \mathrm{HE}$ tutors who either teach in a blended learning environment or virtual classroom. This research adopted a phenomenological qualitative approach and data were collected through focus groups and one-to-one interviews. The study concluded that online collaborative learning offers opportunities for studying outside the standard brick-andmortar classroom and potentially overcoming the problem of overcrowded classes. Although such option has certain advantages, it also presents its own challenges. Tutors acknowledged the benefits of online collaborative learning; however, the tutors also raised some cultural and pedagogical concerns they deemed as hindrances to the learning effectiveness as a whole. Recommendations concerning the effective implementation of online collaborative learning are given.
\end{abstract}

Keywords: Online Collaboration; Egyptian Higher Education; E-Learning: Online Collaborative Learning; Overcrowded Classroom 


\section{Introduction}

World Bank (2017) reported that many countries with limited resources are having difficulties to finance the escalating number of student and maintain quality of education at the same time. The Egyptian higher education is characterised by serious imbalance in teacher supply and student demand. Egypt is consistently ranked among top performing countries in university enrolment; however, it is ranked among poorest performing nations in terms of education quality (PwC, 2019). Egypt is ranked $100^{\text {th }}$ (out of 137 countries) in terms of higher education and training (Schwab, 2015, p. 110). The Egyptian higher education system produces thousands of graduates every year, and yet the number of unemployed graduates is on the rise (OECD, 2010). The "free education for all" government policy has been implemented in Egypt since the 1950s, which leads to a number challenge as the population growth and demand for education surpass resource availability and teacher supply. Moreover, most lecture halls in Egyptian either reach or exceed the maximum seated capacity. In the internet age, however, online learning creates an alternative teaching delivery to accommodate rising demand for education without the need to increase room capacity.

This paper will examine higher education in Egypt, the problem of overcrowded classes and discuss the challenges of e-learning in Egyptian higher education institutions. This paper will also investigate the view of educators regarding the use of e-learning in Egypt. Finally, recommendations will be made on how to improve the delivery of e-learning in Egypt.

\section{Higher Education in Egypt}

Egypt has a highly subsidised public higher education system. The higher education system in Egypt is free and open to the masses, leaving the public institutions with scarce resources. Majority of the spending goes to operating expenditure of the public universities -- namely paying salaries for the administrators and educators -- and little goes for capital expenditure $(\mathrm{PwC}, 2019)$. Building and campus facilities are poorly maintained (Richards, 1992) and require repair (Holmes, 2008). Educators and students mainly rely on basic textbooks due to lack of access to supplementary reading material (Richards, 1992), computer (Nassef and Osman, 2000), and proper learning equipment needed in science and medical studies (Holmes, 2008). Most university auditoriums and lecture halls in Egypt do not have the seated capacity to accommodate the massive influx of students (Holems, 2008; OECD, 2015; Richards, 1992).

Since the 1970s, the policymakers in Egypt have been facing a long-time challenge to allocate educational resources effectively (Richards, 1992). With a growing population of over 100 million people (Al Tamimi \& Company, 2018), Egyptian universities are often cited as overcrowded (El-Gamal and El Aziz (2012), under-funded (Al Tamimi \& Company, 2018), under-performing (Lindsey, 2012), and "not serving the country's need well" (OECD, 2010, p. 13) due to limited resources. As the population increases, there must be an accompanying emphasis on increasing the quality of education at all levels. However, the quality of higher education in Egypt is constrained by large class size, meagre faculty salaries, as well as insufficient learning materials and equipments (Al Tamimi \& Company, 2018; Holmes, 2008; Richards, 1992).

International Journal of Management and Applied Research, 2019, Vol. 6, No. 2 
The "free education for all" government policy is a challenge for the national economy and labour market. Reports from the World Bank (Richards, 1992; Schwab, 2015) found that Egyptian universities have a high level student enrolment in the Arab region. In the academic year 2016/2017, 3.3 million students enrolled in higher education (CAPMAS, 2019). The World Education Service (2018) recently stated that student enrolment in Egyptian higher education had increased from 31 percent in 2014 to 34 percent in 2016. With the projected population growth, the Egyptian higher education system is expected to enrol additional one million students in 2021/22 (PwC, 2019). However, the university campus has been unable to cope with the surge of student enrolment. Some lecture halls were 200 percent over its intended capacity, with seating capacity of 500 persons filled with 1500 students (Holmes, 2008). This is partially due to limited budget for infrastructure and facility that subsequently impedes the provision of sufficient seating capacity (Al Tamimi \& Company, 2018). The overcrowded classroom is the focal point of this study and the next section will discuss this issue in depth and its impact on Egyptian higher education.

\subsection{Overcrowded classes}

The admission policy in Egyptian higher education is highly driven by socio-political considerations (Nassef and Osman, 2000) and it disregards individual preference in university admission (OECD, 2015). The basis for student selection is largely supplydriven rather than based on student preference (OECD, 2010), and thus "students might have been disadvantaged by the meritocratic admission strategy" (Emira, 2014, p. 31). The university admission is totally relied on the secondary school leaving examination -- Thanaweya Amma. A high score in the exam results leads to admission in majors with high salary or social prestige, whereas a low score in the exam either results in no university admission or admission into programmes with fewer job opportunities (Holmes, 2008). If a course or programme is overenrolled, "surplus students are compulsorily assigned to other programmes within the same institutions and are not allowed to opt for other preferences within or outside those institutions" (OECD, 2015, p. 118). Such practice leads to a growing number of the unemployed graduates who have little or no interest in their field of study (OECD, 2015). The outcome is an oversupply of educated unemployed, skill mismatch, and constrained labour market (OECD, 2010).

Students are more likely to receive more support and attention in a small class setting than a larger one. At the university level, the average student-faculty ratio is 15 across OECD countries, meaning 15 students per class (OECD, 2018). According to the Central Agency for Public Mobilization and Statistics (CAPMS) (2019), the average student-teacher ratio in Egyptian universities rose from 21 in 1990 to 33 in 2016/2017. In Egypt, it is not uncommon for students to attend class in a lecture hall with more than twice its seated capacity (Holmes, 2008; El-Gamal, 2014; Richards, 1992). Students are forced to arrive class three hours early (Richards, 1992), sit on the floor (Holmes, 2008), or adopt a rotation system in which a group of students take turn in attending class (Richards, 1992). The high class densities and overcapacity not only have an impact on structural integrity but also learning outcomes.

International Journal of Management and Applied Research, 2019, Vol. 6, No. 2 
The rising number of student enrolment further stretches the already limited resources of universities in the country. Habibi and El-Hamidi (2015) warned that a lack of investment in higher education risks damaging the quality of education in Egyptian higher education and the value of university degrees. Many classrooms are poorlymaintained and ill-equipped (Richards, 1992; Holmes, 2008). The university libraries are under-funded and there is limited amount of books and academic publications available for students (Richards, 1992). Some university campuses have been the sites for political instability and unrest with student unions staging protests in front of the Higher Education Ministry due to inadequate educational resources and funding (Habibi and El-Hamidi, 2015; Emira, 2014).

The rapid population growth implies that demand for education will continue to increase and the main challenge for educators and policymakers is to improve quality of education in a cost-effective manner. One of the main determinants of the economic cost of education is the student-teacher ratio (Krugger, 2003). At institutional level, a large class (with over 100 students) is a cost-effective strategy to prepare student working in diverse global environment. However, critics argued that large class size has negative effects on learning effectiveness because large class size affects effective communication between tutor and student, and the student may feel unable to raise issues or questions (Gibbs and Jenkins, 1992). Educators are required to put extra efforts to accommodate different learning needs in a large class size (Gibbs and Jenkins, 1992; Orellana, 2006). In addition, educators may find it challenging to adopt a student-centred approach in a large class setting, mainly due to the difficulty in engaging students and inability to teach effectively in a crowded classroom (Gibbs and Jenkins, 1992). In recent years, however, technological advances have influenced learners at all ages and education across the globe. The rise of e-learning and the subsequent Massive Open Online Courses (MOOCs) not only enable educators to reach global audiences but also allow learners around the world to learn at their own pace.

The Egyptian Government has recognised the need to reform higher and further education, and initiated Higher Education Enhancement Project which is aided by a US\$50 million loan from the World Bank (Independent Evaluation Group, 2011). The project aims to improve quality of university education and vocational training through educational technology and quality assurance mechanism. In 2008, 17 Egyptian universities were connected to the broadband; additionally, videoconferencing, digital library, and e-learning facilities were implemented in all universities (Independent Evaluation Group, 2011). The Higher Education Enhancement Project illustrates the importance of educational technology in preventing overcrowding issue in physical classroom and meeting the demand for higher education, which in turn, develops the kind of workforce which the country needs. As Welsh et al. (2003) argued, e-learning courses are not constrained by room capacity and number of educator, and therefore, avoiding the physical discomfort in an overcrowded classroom. The higher education system in Egypt could possibly benefit from the flexible aspect of online learning; which could be a partial solution to the overcrowded classroom (El-Gamal, 2014).

El-Gamal and El Aziz (2012) conducted a research on the perception of Egyptian university students and academics on the use of e-learning. According to their findings,

International Journal of Management and Applied Research, 2019, Vol. 6, No. 2 
academics perceive e-learning as a partial solution to problems in Egyptian higher education system, namely overcrowded classes. E-learning is also perceived as costeffective by the academics due to savings in transportation and expansion of classroom. El-Gamal and El Aziz (2012) also found that majority of the students who participated in the study are aware of e-learning and nearly half of them prefer elearning mode; however, little is known regarding the relatively low preference for elearning. El-Gamal and El Aziz (2012) suggested that Egyptian students resist to change and fear of uncertainty and thus not many of them prefer e-learning. It is possible that the provision of e-learning is still at its early stage in Egypt and thus affects user experience and also preference. There are many issues that factor into an effective implementation of e-learning which are discussed in the next section of this study.

\section{E-Learning in Egyptian Higher Education}

There are several initiatives to promote the use of educational technology in Egypt. Egyptian Knowledge Bank (EKB) is a government initiative aims at creating an online repository of information for the Egyptian citizens of all ages, from pre-schoolers to academics. The Ministry of Communications \& Information Technology (MCIT) established Egypt Information and Communication Technology Trust Fund (Egypt ICT Trust Fund) to promote computer literacy among all Egyptian citizens. In 2012, the trust fund has created Universities Ideas Bank at Cairo University to help develop communication, marketing and ICT skills to enhance employability (Egypt ICT Trust Fund, 2019).

The Egyptian government has introduced a number of e-learning projects over the past decade. Founded by MCIT in 2004 the e-Learning Competence Centre (ELCC) develops online courses, in Arabic and English, to university students and local businesses. Originally designed to help all Egyptian universities to establish eLearning centre in each university, National E-learning Centre (NELC) is now responsible for quality control and monitor online courses offered by the Egyptian universities. NELC also provides training and supports for academic staffs and university students as well as digitise teaching materials and create digital library for academic purpose.

Online learning is commonly used for continuing professional development and professional training in Egypt, especially formal training for police service (Open University, 2018). At the time of writing, each university in Egypt has its own elearning centre. In addition to the established local public universities, there are four higher education institutions offer online courses for Egyptians. Established in 2008, Egyptian E-learning University is a private non-profit university offers distance education for learners in Egypt and neighbouring Arab countries. Other e-learning providers include Arab Open University which opened a branch in Cairo, whereas Mediterranean Virtual University and Avicenna Virtual Campus are networks of universities that deliver online courses collaboratively.

International Journal of Management and Applied Research, 2019, Vol. 6, No. 2 


\subsection{Connectivity}

Given that internet connection and digital devices are essential to the implementation of e-learning, a review of the connectivity in Egypt is important to understand the institutional preparedness for adoption of e-learning. In 2008, $60 \%$ of the computers in all universities are connected to the internet (Independent Evaluation Group, 2011). A decade later, the internet penetration rate reached 48\% in 2018 (Ministry of Communications \& Information Technology, 2019). Open University (2018) reported that students often experience server problem and poor download speed when watching educational videos online. These technical problems are not highly unusual in developing countries; however, these problems do affect learning experience and progress.

\subsection{Learning culture in Egypt}

Rote learning and memorisation are still the dominant modes of teaching in Egyptian universities. University students in Egypt memorise what they learned from the textbook, often without being challenged to apply theory into practice or demonstrate how basic principles might be used in a fictional situation or problem (Richards, 1992). The overemphasis on memorisation and rote repetition of facts leaves no room for developing creativity and critical thinking skills. Learning is more likely to occur when students are able to make sense of they have learned from the tutor and recognise when and what conditions to apply them.

\subsection{Online learning culture}

It is equally important to have a learning environment that encourages interaction between and among learners and instructors. A supportive learning culture, where academic discussion is facilitated and supported by instructor, encourages student participation and develops communication skill. Unlike traditional classroom, online courses encourage participation from all students through interaction. Online discussion forum is the core element of e-learning in order to facilitate purposeful critical discourse and self-reflection. One major drawback of chalk and talk pedagogy is the absence of two-way communication between learners and instructor. In online discussion, students are required to share their thoughts and ideas with the class in a threaded format, so that participants can follow multiple discussion topics over a certain period of time. In addition to text-based communication, some online courses are provided with audio and visual presentation. Taking these together, e-learning offers an alternative mode of learning for Egyptians and potentially bridges the skill gap. The following section presents the underpinning theoretical background pertinent to the research, with a specific focus upon online collaborative learning theory.

\section{Theoretical framework}

There are various instructional designs that help instructors to facilitate and support teaching in an online context. For example, Bonk and Zhang (2009) proposed "Read, Reflect, Display, and Do" model (R2D2) for educators to enhance technology-based teaching for all learning styles. The R2D2 model consists of four phases, with each corresponds with four types of learning styles (linguistic, visual, kinaesthetic, and observational).

International Journal of Management and Applied Research, 2019, Vol. 6, No. 2 
- Read Phase: The "Read" phase is about acquiring knowledge through various mechanism including reading materials or non-text materials such as video and audio files.

- Reflect Phase: the "Reflect" phase refers to self-checking and reflection on content, which suits the learning of observational learners who observe, listen, and take time to assimilate information before reaching at conclusion.

- Display Phase: the "Display" phase represents visual learners who learn by using visual aid, chart, mind-map, graphic, flowchart, and video. In this phase, learners learn by producing visual presentation and consuming visual data.

- Do Phase: this phase aims to encourage hands-on practice or experimentation with the learned content. In this phase, learners demonstrate what they have learned either by solving problems in a simulation, analysing cases, or posting a report. The "Do" phase is more suitable for kinaesthetic learners who prefer "hands-on" experience and physical activities.

Figure 1 illustrates the relationships between these four phases and learning styles in R2D2 model.

Figure 1: "Read, Reflect, Display, and Do" (R2D2) Model for online learners

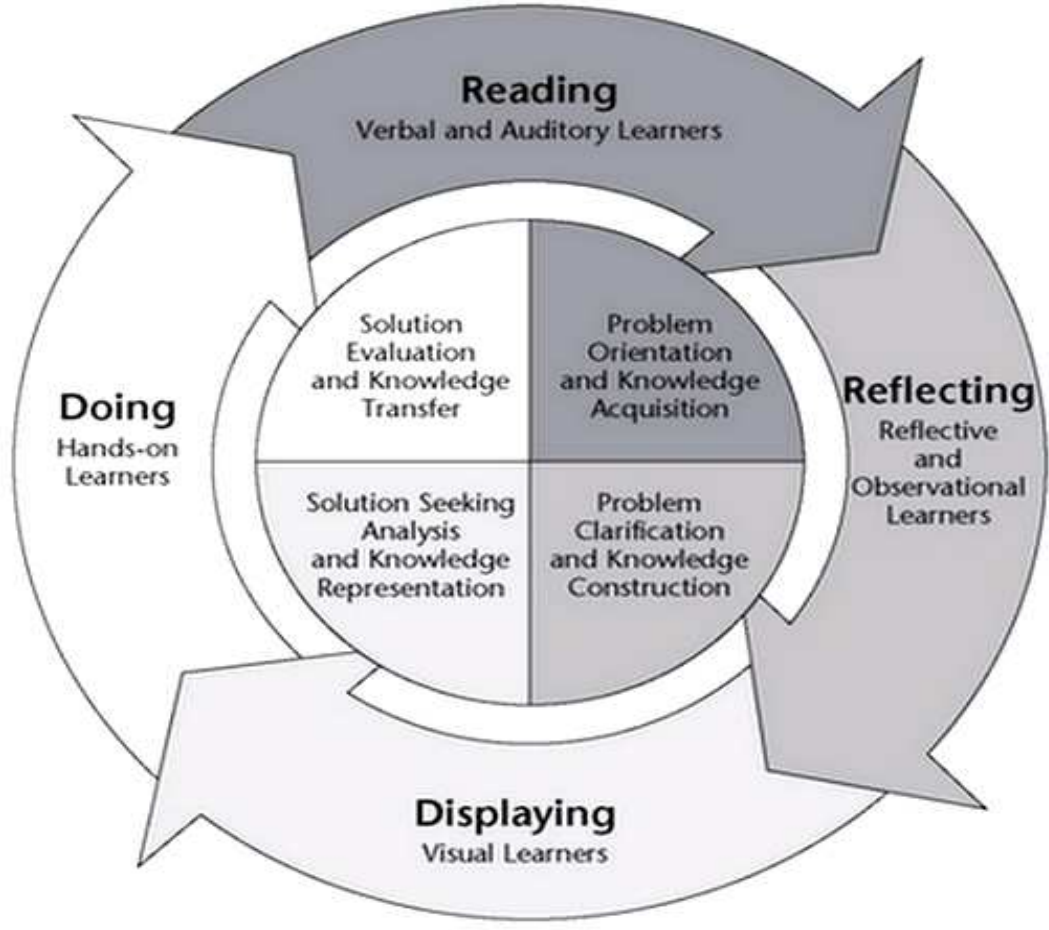

Bonk and Zhang (2009, p: 6)

The R2D2 model provides guidance for online learning, but it does not weigh on the role of peer-to-peer collaboration. The lack of peer-to-peer support and interaction has

International Journal of Management and Applied Research, 2019, Vol. 6, No. 2 
been identified as key factor that caused online learners to drop-out (Blass and Davis, 2003). Harasim (2012) proposed online collaborative learning (OCL) theory as a particular type of constructivist teaching that takes the form of instructor-led group learning to online learning environment. Online collaborative learning theory is based on the principles of constructivist, which recognises learning as a socially mediated process (Vygotsky, 1978) in addition to the use of internet technology. For Harasim (2012), discussion-based pedagogy is insufficient for learning or knowledge construction. Furthermore, students need "to be informed and guided by the norms of the discipline and a discourse process that emphasises conceptual learning and builds knowledge" (ibid, p. 90). In an OCL setting, students are encouraged to collaboratively solve problems through critical discourse instead of memorising facts. Instructors play a crucial role as a facilitator as well as a member of the knowledge community.

Harasim (2012) focuses on the importance of three key phases of knowledge construction:

Idea generating: this is where a group 'brainstorm', which gives the students a starting point for their learning within the online forums.

Idea organising: this is where learners analyse, compare, and contrast their ideas.

Intellectual convergence: this is where the learners reach a level of understanding, consensus, and intellectual synthesis, usually through the group work.

The absence of tutor facilitation has led to some students feeling overwhelmed by the excessive information from the internet and some difficulties in online navigation (Dixon et al., 2008). As consequence some students may resist, lose motivation and disengage (Palloff and Pratt, 2007). Figure 2 illustrates the core design principles of online collaborative learning.

Figure 2: Pedagogy of group discussion

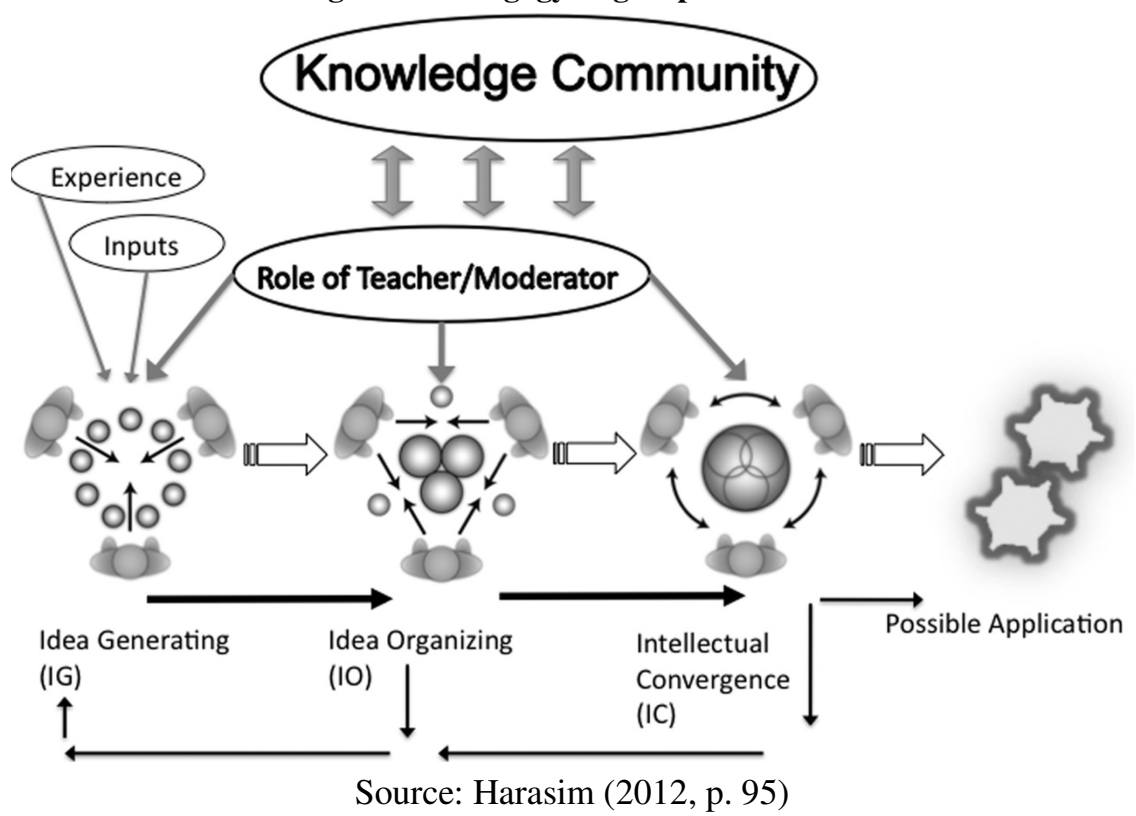

International Journal of Management and Applied Research, 2019, Vol. 6, No. 2 


\section{Methodology}

This research is explanatory and descriptive in order to investigate whether online collaborative group work helps to resolve over-crowded classes. The context was the Egyptian Higher Education system and participants were $20 \mathrm{HE}$ tutors who were teaching in a blended mode (face-to-face and online learning environment). An interpretive attitude of thinking which understands meaning and interaction between these elements, served as the philosophical perspective for this research. The research design for this study is phenomenological interpretive, and the instruments used for collecting data included focus groups and semi-structured interviews which gathered descriptions of lived experiences which were then reflected upon and analysed. This point of view is supported by Van Manen (2017) who claimed phenomenology is a project of thoughtful reflection on lived experience.

\subsection{Purposive Homogenous Sampling}

The researcher purposefully selects a sample that adequately represents the target population on the basis of these variables. In this study, purposive sampling was identified as the most appropriate method for sampling participants, since it focuses on the particular characteristics of a population (HE tutors), namely that of interest in and experience of online learning, the presence of which best assists in addressing the study purpose.

Homogeneous sampling was employed in this study as it enabled certain locations or people to be selected because they possessed similar characteristics. According to Guetterman (2015), the individuals or locations that possess the desired similar characteristics need to be identified by the researcher when adopting homogenous sampling. For the purposes of this study, the desired individual characteristic was online HE tutors both practicing and having experience of online teaching in HE, and the location was the Egyptian HE environment.

\subsection{Sampling criteria}

The sampling frame for this study was a list of 18 universities in Egypt: one online university and 17 universities that deliver online courses.

All universities were contacted through an email which was sent to the relevant academic faculty with details of the proposed study. Positive replies were received from four universities: two were able to accommodate the proposed timeframe in terms of data collection, while the other two asked to reschedule data collection to a period following student examinations. Because of the research timeframe, data collection proceeded with the faculties from the first two universities. The first faculty was located in the North of Egypt, which established a department of "Instructional Technology" to educate tutors on how to teach in a virtual learning environment and communicate with students verbally and visually using online technology. The second faculty is located at the capital of Egypt, Cairo.

\subsection{Participants}

All tutors who teach online courses across the disciplines at the two universities were emailed to ask if they would be their willing to participate in this study. 20 online

International Journal of Management and Applied Research, 2019, Vol. 6, No. 2 
tutors replied and agreed to participate in individual interview and focus group. Participants include both men and women. Table 1 below summarises the demographic profiles of the research participants.

Table 1: Participants' background

\begin{tabular}{llr}
\hline Characteristic & & Number of tutors \\
\hline \multirow{3}{*}{ Online teaching experience } & $2-3$ years & 10 tutors \\
& $3-5$ years & 5 tutors \\
& $7-10$ years & 5 tutors \\
Teaching environment & Online learning & 5 tutors \\
& Blended learning & 15 tutors \\
Gender & Male & 9 tutors \\
& Female & 11 tutors \\
CPD provided to tutors & Online authoring tools & 20 tutors \\
& Soft skills in online delivery & 5 tutors \\
Age & $30-40$ years & 15 tutors \\
& $40-50$ years & 3 tutors \\
& $>50$ years & 2 tutors \\
Main duties & VLE design & 7 tutors \\
& Teaching & 20 tutors \\
Location of the University & Ruthoring online modules & 5 tutors \\
& Urban area & 5 tutors \\
\hline
\end{tabular}

\subsection{Data Collection}

All participants took part in the interviews and focus groups. The main reason for using interviews in this study is that interviews provide flexible, spontaneous, explicit and immediate responses (Flick, 2006). In this study, interviewees narrated their professional experience in teaching and their understanding of online education in Egypt.

Additionally, this study also adopts focus group as data collection method because it allows participants to build upon ideas and give spontaneous views on the subject matter (Bryman, 2012). The participants were given options to join four different focus groups (FG1, 2, 3, 4), and each has different time slot and location. Each participant selected the group they would join based on their preference and time availability.

\subsection{Data Analysis}

Interpretative Phenomenological Analysis (IPA) was used to analyse the data. Smith et al. (2010) pointed out that IPA is an approach to analyse data in a qualitative research with an idiographic focus, which means it has a focus on the particular rather than the general. More specifically, IPA requires small sample size and it weighs on detailed, reflective, rich data in order to develop insightful analysis.

International Journal of Management and Applied Research, 2019, Vol. 6, No. 2 


\section{Data and Findings}

This section first reports the challenges and issues that tutors experience in overcrowded face-to-face classes. Next, the merits or issues concerning online social collaboration as a response to the face-to-face classes are outlined in the following four sections: a) the impact of online learning on social collaboration/isolation; b) methods of social communication; c) the role of the tutor in encouraging and maintaining social collaboration, and d) the advantages and disadvantages of online forums as a proposed method of social collaboration.

\subsection{Over-crowded face-to-face classes}

When discussing overcrowded classes, tutors focused on three issues: the challenges for tutors, the impact on learning, and possible solutions.

Most commented on the challenges they faced and recognised the difficulty to facilitate their teaching strategies in overcrowded classroom. For example, in FG3 and FG4, discussion was centred on learning effectiveness for individual learners in large class setting. Over-crowded classes were deemed as the main obstacle to knowing each individual learner. Tutors referred to the impact of overcrowded classes and there was an agreement that overcrowded classes led to a decline in teaching quality and overall student experience. For example, during an individual interview P19 mentioned that in the social science faculty, students may never get to know their classmates as the number of students in an academic year often exceed 2000 students. In FG2, two tutors were of the view that class sizes greater than 10 students can lower the quality of learning and teaching, while in FG3, class sizes should not exceed 50 students, several tutors in FG1 agreed that, online learning is suitable for a large number of students in class.

Several tutors proposed some solutions to the over crowdedness of classes. In FG2, P7 and P8 both agreed with the view that online learning could turn the problem of overcrowded classroom into a conductive learning environment. Furthermore, there was a common view that online education is more cost-effective than traditional brickand-mortar settings. Some of the tutors in FG2 and FG4 suggested privatisation of higher education. However, this suggestion was disagreed by others because the current political parties remain unwilling to privatise Egyptian higher education for the time being.

\subsection{The impact of online learning on collaboration and social isolation}

In the focus group discussions, tutors had a number of different views concerning social collaboration and social isolation in online learning. Some tutors were optimistic about the interactive features of online learning platforms for students. Among these optimistic tutors, some stated that the anonymity of online learning is particularly appealing for introverts or those who have difficulties socialise with others. One tutor stated: "One of my students expresses himself better when he is behind the screen than face to face" (FG4, P17). Three more tutors were of the opinion that students who were socially confident by nature, an online learning environment maximises their natural tendencies and widens their social network. P9 in FG2 commented "Online

International Journal of Management and Applied Research, 2019, Vol. 6, No. 2 
learning allows students to explore diverse backgrounds, languages and cultures, to communicate and collaborate with students from different areas."

In FG4, one tutor mentioned the transition from secondary education to tertiary education from a gender perspective. In areas with conservative traditions, male and female students attend classes separately in pre-tertiary education, while the sexes are not separated in the classroom at university level. P13 in FG3 stated, "In the face-toface learning environment, girls are normally shy and try to avoid talking to boys as much as possible". Another tutor in the same focus group agreed and added that in this case e-learning provides a more appropriate social environment, where male and female students can work collaboratively more freely compared to face-to-face class. In FG2, two tutors agreed that online learning provides a good opportunity for female students to socialise and expand their social network; and perhaps more effective than face-to-face since they can meet friends anytime and anywhere without leaving their homes.

On the other hand, a few tutors strongly expressed their opinion that online learning can lead to social isolation. Two tutors, in FG1 and FG3 respectively, argued that this was an issue that affected all students since the physical and temporal separation between and among tutor and student can develop a sense of isolation. As one tutor stated: "Avatar replaces Muhammad" (FG1 Int1). In the individual interview another tutor (FG4, P17) commented that many students preferred checking their friends' Facebook updates or posting messages rather than chat with their friends face-to-face.

Some of the tutors in FG4 were more pessimistic about the interactive feature of online learning, based on the view that online learning would minimise oral communication thereby reducing opportunity to talk, especially for introverted students. Some tutors from FG3 also share similar concern. Both groups recognised the impacts of individual differences and learning styles to learning, and believe that if a student has a difficulty to interact with others, this student may exhibit the same behaviour online as they do in a physical classroom.

\subsection{Methods of social communication}

The second issue to emerge from the data was related to the different methods recommended by online tutors for online collaboration. Most tutors in the focus groups tended to endorse social networks, explaining that through these sites, students can chat, comment, discuss, and share resources. Two tutors in FG2 and FG4 were of the opinion that social networks work well to break the ice between students in online learning, and another added that, through these social networks, students could stay up-to-date regarding timetables, examinations, and assigned tasks.

However, majority of the tutors had a negative opinion of Facebook. For example, P13 in FG3 stated "Facebook is an open and informal network, so it is unreliable". While several made mention of Wikis and Blogs, others were hesitant about recommending sites at all. Majority of the tutors approved of social forums which were part of the Learning Management System (LMS); some added that they recommended social forums in the LMS on the condition that they were fully monitored by the university

International Journal of Management and Applied Research, 2019, Vol. 6, No. 2 
server. One of the tutors stated "social networks should be restricted to the topics discussed only, no side topics that allow learners to drift away" (FG1, P5).

\subsection{The role of the tutor in encouraging and maintaining social collaboration}

This section corresponds with Harasim's final position (2012) about the critical role of the tutor in the construction of knowledge, not only through facilitating the process and providing resources to the group, but also through ensuring that the core concepts and practices of the subject domain are fully integrated. According to the research data, all tutors agreed that it is part of the online tutor's role to maximise and maintain social collaboration between online students. Two tutors suggested the tutor needs to initiate some activities, including sharing and commenting. Several mentioned the importance of the tutor's role in selecting group members to form homogenous groups that work together successfully. In a one-to-one interview, P9 in FG2 explained that, in some groups, one person dominates whereas others are marginalised. This tutor stated "Some group members monopolise the discussion and impose their ideas on others". Notably, this was a point mentioned by tutors who had concerns about group work and had a negative experience with working in groups in the past. Another aspect on which tutors agreed was students need to be monitored closely in online collaborative work.

\section{Advantages of online forum}

One tutor (FG3, P15) suggested that it requires less effort for the online tutor when the students are motivated to learn. Another advantage of social collaboration, mentioned by one tutor in FG4, is that when students socialise, discuss, comment, agree and disagree, they feel that they take an active role in learning. Two other tutors (FG2, P8 and FG4, P16) think that student motivation is central to study online.

A few tutors brought up the idea of student-student interaction in online forums. P8 and $\mathrm{P} 9$ discussed the steps of this interaction, with online students get to know each other first, then proceed with exchanging information and experiences with each other. Further, P10 in the same focus group suggested that, at this point, it is likely that these students may start thinking together and elaborate on their thoughts together.

Student-tutor interaction was mentioned as another type of interaction by P18 and P19 in FG4. P18 commented that interaction is a two-way influence between student and tutor, stating that "there is tutor-student interaction where I get to know my learners through interacting and socialising with them."

\section{Disadvantages of online forum}

Conversely, there were disadvantages to online social collaboration which caused concerns for some tutors. Two tutors in FG2 and FG4 commented that they would limit collaboration to minimum due to concerns about non-contributing group members and unequal workload between group members. In FG2, a tutor in their oneto-one interview, confirmed "I recommend social forums but excluding the social aspect from them". When asked about the meaning of "excluding the social aspect" in social forums, the tutor explained: "If the group is closed, private and members are assigned only by the tutor, this means that this is a socially excluded group". There were also tutors who believed that online social forums were simply not for learning. In FG1, P6 went as far to describe it as “... a waste of time”.

International Journal of Management and Applied Research, 2019, Vol. 6, No. 2 
Two tutors in FG1 and FG4 highlighted their concerns about assessment in the form of questions: "If a student gives wrong information to another student in an online group work, how can you as a tutor know? How do you correct this wrong information? How can I know what they learn from each other? How can I make sure that what they learn is useful and correct?"

A number of tutors repeated what had been said on the role of tutors in guidance and monitoring as discussed earlier, but the tutors who had raised the questions did not seem fully persuaded. The tutors who had discussed the influence of the individual differences between students in their social collaboration and the issue of isolation also lead to a number of concerns. In FG3 and FG4, a few agreed that, for some students, forums were distractive, claiming students relied on the tutor as the only source of knowledge, and any knowledge from any other source served as a distraction. Losing student's attention was raised as a concern by two tutors in FG4, one of them again mentioned that when students work collaboratively, the tutor is not the only source of information in the session. Another tutor (FG2, P8) added that as a consequence, a student will not be attentive in listening to the tutor anymore, since there are others who can be sources of information. Another tutor, who in general had a positive perception of students' online communication and collaboration (FG1 P1), highlighted that group discussion in group work can end up discussing topics away from the course syllabus. This view is shared by other participants in the same focus group, and stresses the importance of following course syllabus and time frame.

In the final debate between advantages and disadvantages of group work, in FG2, two tutors confirmed that group work requires preparation, promotion, and education. P8 stated "Not all students know how to either criticise others or how to respond to criticism". Finally, P1 mentioned the political demonstrations and the following unrest in Egypt with regards to higher education reform, a topic he prefers to avoid.

\section{Discussion}

Tutors in this study acknowledged the benefits of online learning. However, they expressed a number of concerns about the use of online collaborative works in Egyptian higher education. Tutors explained that it is a challenge to accommodate different learning needs especially when the groups are heterogeneous with regard to their skills and learning behaviour. The issue of social loafing is not uncommon in face-to-face setting; the tutors of this study also noticed that some students tend to exert less effort in online group projects than working alone. It is difficult for the tutors to constantly monitor learning progress in a large class setting. Furthermore, some tutors noticed that online collaborative works actually create social isolation for students who are more introverted.

Another main concern that was highlighted in the findings for online group work is the need to handle disagreement and defuse conflict. Therefore, some tutors preferred to avoid online group work and preferred individual tasks. According to Cohen and Lotan (2014, p. 57), "vigorous disagreement is one of the positive features of cooperative learning", where students realise that there is more than one legitimate perspective for

International Journal of Management and Applied Research, 2019, Vol. 6, No. 2 
the same problem. However, students may exhibit antisocial behaviours if their views are rejected by other members of the group; subsequently, tutors are understandably overwhelmed and distressed (Cohen and Lotan, 2014). Oakley et al. (2004) explained tutors face two main challenges in group work: firstly, team work requires students to develop strong communication, coordination and conflict resolution skills, which not all tutors feel qualified to teach; secondly, fair assessment could be difficult due to social loafing and it requires thoughtful consideration of learning objectives and a combination of assessment approaches.

As a start to embed collaborative work to overcome the aforementioned challenges, a conceptual change is needed in teaching approach and learning behaviour. This means that both learners and instructors should be more open to the idea of constructive criticism and respectful disagreement. Tutors also need to set clear guidance on online classroom behaviours, remark what kind of behaviours are deemed inappropriate and should be avoided (Cohen and Lotan, 2014).

In summary, there are many advantages and disadvantages of embedding collaborative online work into the Egyptian higher education system. On the positive side, the use of online learning platform appears promising in the context of Egyptian higher education for economic reasons. For university administrators, virtual classroom costs less than a physical room. As Welsh et al. (2003) claimed, online environment eliminates the need to enlarge room capacity to accommodate greater number of students. For university students, the flexibility of online learning allows them to study at their own pace and convenience, thereby allows them to work and study at the same time. The flexible aspect of online learning is particularly important to Egyptians who need to fulfil their financial responsibility towards their family (El- Gamal and El-aziz, 2012). Additionally, online collaborative works provides an alternative mode of learning where students communicate, collaborate, plan, synthesise and evaluate their work.

On the negative side, tutors raised their concerns about online group work for the following reasons. First, online collaborative works may reinforce social exclusion because ethnic minorities and disabled students may feel isolated from their peers and the lack of experience in communicating with the minorities discourages the ethnic majorities to interact with the minorities. Second, tutors encountered students with varied level of digital preparedness, and thus believe that students should prepare themselves better before undertaking online courses. Third, tutors struggled to identify individual contribution to a group work due to problems such as free-riding and social loafing. Group work itself presents a number of problems, namely personal conflicts between group members, unwilling to collaborate, and inability to compromise. These problems occur in both virtual and face-to-face environment, however.

\section{Recommendation and Conclusion}

Large class size is one of the main challenges in Egyptian higher education. Embedding online collaboration into course syllabus can help to develop skills that are necessary in an increasingly digitalised global economy. While the tutors in this study acknowledged the benefits of online collaborative learning, some tutors gave negative feedback regarding group work due to the following reasons. From a cultural

International Journal of Management and Applied Research, 2019, Vol. 6, No. 2 
perspective, there is a cultural resistance to online learning among Egyptians. This finding is consistent with the study of Open University (2018) and El Gamal and El Aziz (2012). From a pedagogical perspective, tutors expressed their concerns about the difficulty to identify and assess individual contributions of each student in a group project. A common method to solve this problem is to let team members quantify their contributions by themselves. Such peer assessment involves students in grading and thus empowers students to take responsibility for their own learning.

All tutors in this study agreed with the view that virtual classroom is useful and partially solve the problem of overcrowded physical classroom. Nonetheless, teaching online is an educational challenge itself. The skills and knowledge required for an effective online instructor differs from the conventional chalk-and-talk lecturer. Facilitating meaningful discussion and keeping students engaged in an online context require a student-centred approach. For autonomous learning, R2D2 model (Bonk and Zhang, 2009) is recommended for Egyptian instructors because it outlined a number of learning activities for different individual learners. Bonk and Zhang (2009) use Read, Reflect, Display and Do, as organising categories and suggested over one hundred leaning activities for online instructors. At the time of writing, it appears that the tutors in Egypt mainly adopt text-based online discussion in their teaching, without considering the use of audio and video formats in teaching and assessing students' understanding of the theories. For example, student-produced video has been recognised as a viable assessment (Avramenko and Begum, 2018), which could be adopted in online courses. For collaborative learning, Harasim's OCL theory (2012) emphasises the interactive aspect of collaborative learning in an online context. This form of learning weighs on peer-to-peer collaboration and the role of instructor to facilitate meaningful discussion.

The Egyptian higher education system is in need of a conceptual change at all levels. An introduction of new form of teaching like online collaborative learning is subject to resistance from organisational culture and many individuals, namely students and educators. A conservative culture, fears of uncertainty, overprotection of current practices all constitute to resistance to any meaningful change in teaching. An understanding of the nature of change as well as regular communication can be useful in facilitating change. At the individual level, students need to be prepared for learning as a group and understanding virtual classroom etiquette. They need to understand how to handle disagreement and avoid conflict. Tutors need to rethink their teacher-led, one-to-many communication model and consider teaching modes such as online collaborative learning and the use of peer assessment. At institutional level, Academic institutions need to train the trainers and equip tutors with necessary know-how and tools. In academia, educators tend to be conservative and generally sceptical of educational change. For that reason, a highly participatory process and regular communication can help educators to understand and appreciate online collaborative learning. At national level, the state should consider the need to modernise course content and promote collaborative learning countrywide.

\subsection{Research limitations}

This study has research limitations resulting from the data collection method and research scope. Firstly, the research was conducted at two educational institutions in

International Journal of Management and Applied Research, 2019, Vol. 6, No. 2 
the North of Egypt, which is not generalisable to other contexts. In the southern parts of the country, some areas and communities follow conservative traditions in many aspects of life such as clothing and gender segregation in schooling. Therefore, caution must be exercised in studying the perceptions of tutors with regards to academic freedom and responsibility, and the cultural differences here should be taken into consideration as part of further investigation.

Secondly, this study mainly focuses on the perceptions of the tutors regarding online collaborative work, which therefore hides a multitude of other possible topics that may also be worth exploring, such as students' readiness for digitalisation or their acceptance of tutor authority. An investigation into students' perceptions which was not be possible in this study due to the constraints of time and wordage, could help to triangulate the study's findings and answer further related questions that might emerge.

\section{References}

1. Al Tamimi \& Company, (2018), The Egyptian Education Sector: Challenges and Opportunities. [Online] Available from: https://www.lexology.com/library/detail.aspx?g=c46fb983-9c9a-4d6f-88f2$\underline{8 \mathrm{~d} 280032025 \mathrm{~b}}$ [accessed on $15^{\text {th }}$ March 2019].

2. Avramenko, A. and Begum, M. (2018), "Reflections on Practice-Centred Curricula in Teaching Entrepreneurship in Malaysia", International Journal of Management and Applied Research, Vol. 5, No. 3, pp. 135-152. https://doi.org/10.18646/2056.53.18-010

3. Blass, E. and Davis, A. (2003), "Building on solid foundations: establishing criteria for e-learning development", Journal of Further and Higher Education, Vol. 27, No. 3, pp. 227-245, https://doi.org/10.1080/0309877032000098662

4. Bonk, C. and Zhang, K. (2009), Empowering Online Learning: 100+ activities for Reading, Reflecting Displaying and Doing. New York: Jossey-Bass.

5. Bryman, A. (2012), Social Research Methods, $4^{\text {th }}$ ed. Oxford University Press.

6. Cohen. E., and Lotan, R. (2014), Designing Group Work: Strategies for the heterogeneous classroom, $3^{\text {rd }}$ ed., New York: Teachers College Press.

7. Dixon, R. C., Dixon, K. C. and Axmann, M. (2008), "Online student centred discussion: Creating a collaborative learning environment", paper presented at Ascilite Melbourne 2008., Melbourne: Deakin University.

8. Egypt ICT Trust Fund. (2012), Mobile ICT Clubs [Online] Available from: http://www.ictfund.org.eg/page/1418_About [20 April 2019].

9. El-Gamal, S. (2014), An investigation of electronic learning in higher education: The Egyptian context, Doctoral Thesis, Newcastle: University of Northumbria

10. El Gamal, S. and El Aziz, R. (2012), "Improving higher education in Egypt through e-Learning programmes: HE students and senior academics perspective",

International Journal of Management and Applied Research, 2019, Vol. 6, No. 2 
International Journal of Innovation in Education, Vol. 1, No. 4, pp. 335-360. https://doi.org/10.1504/IJIIE.2012.052738

11. Emira, M, (2014), "Higher Education in Egypt since World War II: Development and Challenges", Italian Journal of Sociology of Education, Vol. 6, No. 2, pp. 8-35

12. Flick, U. (2006), An introduction to qualitative research. Oxford, Blackwell press.

13. Gibbs, G. and Jenkins, A. (1992), Teaching Large Classes in Higher Education: How to Maintain Quality with Reduced Resources. London: Kogan Page.

14. Guetterman, T. (2015), "Descriptions of Sampling Practices Within Five Approaches to Qualitative Research in Education and the Health Sciences", Forum: Qualitative Research, Vol. 16, No. 2. https://doi.org/10.17169/fqs16.2.2290

15. Habibi, N . and El-Hamidi, F. (2015), "Why Are Egyptian Youth Burning Their University Diplomas? The Overeducation Crisis in Egypt", Middle East Brief 102, Massachusetts: Brandeis University.

16. Holmes, (2008) "Higher education reform in Egypt: preparing graduates for Egypt's changing political economy", Education, Business and Society: Contemporary Middle Eastern Issues, Vol. 1 Issue: 3, pp.175-185, https://doi.org/10.1108/17537980810909797

17. Independent Evaluation Group (2011), ICR Review: Report Number ICRR13224, [Online] Available from: http://documents.worldbank.org/curated/en/698321474632559308/pdf/0001465 97-20140619170713.pdf [15 March 2019].

18. Krueger, A. B. (2003), "Economic Considerations and Class Size", The Economic Journal, Vol. 113, No. 485, pp. F34-F63, https://doi.org/10.1111/1468-0297.00098

19. Lindsey, U. (2012), Freedom and Reforms at Egypt's university, Washington, D.C.: Carnegie Endowment for International Peace [Online] Available from: https://carnegieendowment.org/files/egyptian_universities.pdf [15 March 2019].

20. Ministry of Communications \& Information Technology (2019), ICT Indicators in Brief [Online] Available from: http://www.mcit.gov.eg/Upcont/Documents/Publications_3042019000_EN-ICTIndicators-in-Brief-March2019.pdf [15 March 2019].

21. Nassef, A. F. and Osman, O. M. (2000), Egypt Human Development Report 1997/1998, Cairo: Institute of National Planning

International Journal of Management and Applied Research, 2019, Vol. 6, No. 2 
22. Oakley, B., R. M. Felder, R. Brent, and I. Elhajj.( 2004), “Turning student groups into effective teams", Journal of Student Centered Learning, Vol. 2, No. 1, pp. 934.

23. OECD (2010), Reviews of National Policies for Education: Higher Education in Egypt 2010, Paris: OECD Publishing, https://doi.org/10.1787/9789264084346-en

24. OECD (2015), Schools For Skills: A New Learning Agenda For Egypt schools For Skills: A New Learning Agenda For Egypt. [Online] Available from: https://www.oecd.org/countries/egypt/Schools-for-skills-a-new-learning-agendafor-Egypt.pdf [15 March 2019].

25. OECD (2018), Education at a Glance 2018, Paris: OECD Publishing, https://doi.org/10.1787/eag-2018-en

26. Open university (2018), Online Learning in Tertiary Education in the Middle East and North Africa [Online] Available from: http://www.open.ac.uk/research/sites/www.open.ac.uk.research/files/files/Docume nts/Online\%20learning\%20in\%20tertiary\%20education\%20in\%20the\%20Middle \%20East\%20and\%20North\%20Africa\%20.pdf [15 March 2019].

27. Orellana, A. (2006), "Class size and interaction in online courses", Quarterly Review of Distance Education, Vol. 7, No. 3, pp. 229-248.

28. Palloff, R.M. and Pratt, K. (2007) Building Online Learning Communities: Effective strategies for the virtual Classroom, $2^{\text {nd }}$ ed. San Francisco: Jossey-Bass.

29. PwC (2019), Understanding Middle East Education [Online] Available from: https://www.pwc.com/m1/en/industries/education/publications/education-countryprofile-egypt.pdf [Accessed on 16 June 2019].

30. Richards, A. (1992), Higher education in Egypt. Washington, DC: World Bank.

31. Schwab, K. (2018), The Global Competitiveness Report 2017-2018, Paris: OECD Publishing.

32. Smith, J. A., Flowers, P., \& Larkin, M. (2010), Interpretive Phenomenological Analysis: Theory, Method and Research. London: Sage.

33. The Central Agency for Public Mobilization and Statistics (CAPMAS). (2019) $3.031 \mathrm{~m}$ students enrolled in higher education in 2016/2017 [Online] Available from: https://www.capmas.gov.eg/ [Accessed on 16 January 2019].

34. Van Manen, M. (2017), "Phenomenology in Its Original Sense", Qualitative Health Research, Vol. 27, No. 6, pp. 810-825, https://doi.org/10.1177/104973231769938.

International Journal of Management and Applied Research, 2019, Vol. 6, No. 2 
35. Vygotsky, L.S. (1978), Mind in Society. Cambridge. MA: Harvard University Press.

36. Welsh, E., Wanberg, C., Brown, K., \& Simmering, M.E-1.E. (2003), "E-learning: emerging uses, empirical results and future directions", International Journal of Training and Development, Vol. 7, No. 4, pp. 245-258, https://doi.org/10.1046/j.1360-3736.2003.00184.x

37. World Education Service (2018), Outbound Degree Seeking Students in Egypt. [Online] Available from: https://wenr.wes.org/2019/02/education-in-egypt-2 [Accessed on 16 June 2019].

38. World Bank (2017), Higher Education. [Online] Available from: https://www.worldbank.org/en/topic/tertiaryeducation [Accessed on 16 Oct 2018].

International Journal of Management and Applied Research, 2019, Vol. 6, No. 2 